Check for updates

Cite this: Chem. Commun., 2020 56, 10662

Received 30th June 2020,

Accepted 3rd August 2020

DOI: $10.1039 / \mathrm{d} 0 \mathrm{cc} 04522 \mathrm{e}$

rsc.li/chemcomm

\section{Fourfold symmetric MCR's via the tetraisocyanide 1,3-diisocyano-2,2-bis(isocyanomethyl)propane $\dagger$}

\author{
Roberto Butera, (D) a Annadka Shrinidhi, ${ }^{b}$ Katarzyna Kurpiewska, ${ }^{c}$ \\ Justyna Kalinowska-Tłuścik (D) ${ }^{c}$ and Alexander Dömling (D) *a
}

\begin{abstract}
Oligoisocyanides are attractive synthetic targets, however, only a few are known. Here, we describe the smallest stable tetraisocyanide possible, the 1,3-diisocyano-2,2-bis(isocyano-methyl)propane (1) with $S_{4}$ symmetry. Its four-step synthesis, structure, and reactivity in unprecedented symmetric fourfold Ugi 4CR and fourfold Passerini 3CR are described. Exhibiting high functional group tolerance and moderate to high yields, we foresee multiple applications of 1,3-diisocyano-2,2-bis(isocyanomethyl)propane, for example in MOFs, COFs, dendrimers, or artificial organs.
\end{abstract}

The isocyanide group is a highly useful functional group in chemistry with applications in organic, inorganic, metalorganic, and medicinal chemistry and also in material science. ${ }^{1-4}$ While the number of monoisocyanides is very large, the number of biisocyanides is sizable, but the number of oligoisocyanides is minuscule by comparison. ${ }^{5-12}$ A representative molecule bearing three isocyanide groups is tris(2-isocyanoethyl)amine, providing access to unprecedented complex structures. By implementing this isocyanide in a threefold isocyanide-based multicomponent reaction (IMCR), Wessjohann and Rivera were able to synthesise complex supramolecules, as hybrid peptide-peptoid podands and macromulticycles. ${ }^{7-9}$ Organic tetraisocyanides are a very rare species of isocyanide bearing compounds; only three synthesised organic tetraisocyanides $(2,3,4$, Fig. 1$)$ are reported to date..$^{10,11,13}$ And, as far as reported, no successful fourfold IMCR was achieved with these tetraisocyanides..$^{10,11,13,14}$

Here, we report the synthesis, structure, and reactivity of the tetraisocyanide 1,3-diisocyano-2,2-bis(isocyanomethyl)-propane (1). Inspired by its symmetry and anticipating numerous unique

\footnotetext{
${ }^{a}$ University of Groningen, Department of Drug Design, A. Deusinglaan 1, 9713 AV Groningen, The Netherlands. E-mail: a.s.s.domling@rug.nl

${ }^{b}$ University of California, Department of Chemistry \& Biochemistry, La Jolla, San Diego, California 92093-0358, USA

${ }^{c}$ Department of Crystal Chemistry and Crystal Physics Faculty of Chemistry,

Jagiellonian University, Gronostajowa 2, 30-387 Kraków, Poland

$\dagger$ Electronic supplementary information (ESI) available. CCDC 2001285, 2001286 and 2002330. For ESI and crystallographic data in CIF or other electronic format see DOI: $10.1039 / \mathrm{d} 0 \mathrm{cc} 04522 \mathrm{e}$
}

applications, our goal was not only to synthesise and characterise this symmetrical tetraisocyanide $\mathbf{1}$ (Fig. 1) but also to utilise it in isocyanide-based multicomponent reactions. ${ }^{15,16}$

We envisioned to synthesise the tetraisocyanide 1 from available starting material pentaerythritol tetrabromide (5) via a short sequence involving the Ugi dehydration of the tetraformamide as the last step (Scheme 1). Nucleophilic substitution reaction of pentaerythritol tetrabromide (5) with sodium azide (12 eq.) yielded the 1,3-diazido-2,2-bis(azidomethyl)propane (6, 88\%). Reduction of the tetraazide 6 by employing hydrogen and palladium-on-charcoal in a Paar apparatus at a pressure of 3 bar yielded in quantitative conversion of 6 to 2,2-bis(aminomethyl) propane-1,3-diamine (7). The tetraformamide 8 was prepared by refluxing the tetraamine 7 in excess ethyl formate. Despite the unusual long reaction time of $48 \mathrm{~h}$, we were able to generate the compound $N, N^{\prime}$-(2,2-bis(formamidomethyl)propane-1,3-diyl) diformamide (8) in $92 \%$ yield. The tetraformamide 8 exhibited extremely poor solubility in most organic solvents which opportunely could be exploited by facilitating the purification of $\mathbf{8}$ by a simple precipitation/filtration/washing procedure (ESI $\dagger$ ).
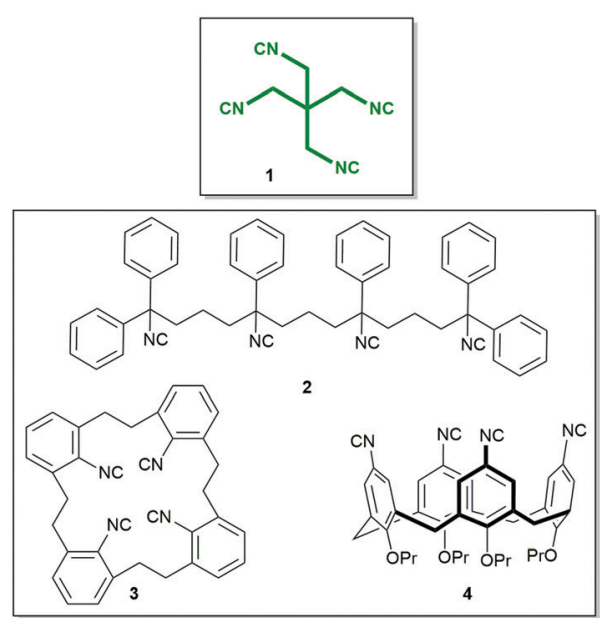

Fig. 1 Tetraisocyanide 1 and previously reported tetraisocyanides $\mathbf{2}, \mathbf{3}$, and $\mathbf{4}^{10-12}$ 
<smiles>N#CCBr</smiles>

5

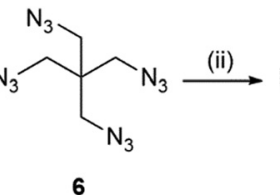

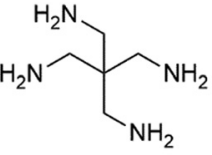

7

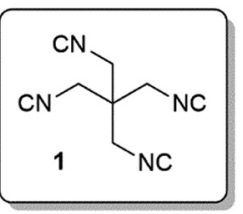

8

Scheme 1 Synthesis of 1,3-diisocyano-2,2-bis(isocyanomethyl)propane 1 (i) $\mathrm{NaN}_{3}, \mathrm{DMF}, 80{ }^{\circ} \mathrm{C}, 12 \mathrm{~h}, 88 \%$; (ii) $\mathrm{H}_{2}-\mathrm{Pd} / \mathrm{C}, \mathrm{MeOH}, 40{ }^{\circ} \mathrm{C}, 20 \mathrm{~h}, 99 \%$; (iii) ethyl formate, $60{ }^{\circ} \mathrm{C}, 48 \mathrm{~h}, 92 \%$; (iv) $\mathrm{POCl}_{3}, \mathrm{Et}_{3} \mathrm{~N}, \mathrm{DCM},-20^{\circ} \mathrm{C}-\mathrm{rt}, 18 \mathrm{~h}, 55 \%$.

Finally, dehydration of the tetraformamide $\mathbf{8}$ was completed using phosphoryl chloride (Scheme 1). Comparably to the reaction leading to compound $\mathbf{8}$ the reaction time required an increase to $18 \mathrm{~h}$ to reach completion. Since the tetraisocyanide 1 showed a similarly poor solubility in most organic solvents, we exploited this property in the workup of the reaction by filtrating the residue and washing with DCM and water yielding in 1,3-diisocyano-2,2-bis(isocyanomethyl) propane (1). Although the yield of the dehydration reaction was $55 \%$, we achieved the synthesis of the tetraisocyanide 1 with a moderate overall yield of $44 \%$ over four steps on a multigram scale.

The tetraisocyanide $\mathbf{1}$ is an off-white and odourless solid with a m.p. range of $215-219{ }^{\circ} \mathrm{C}$ (decomp.). 1,3-Diisocyano-2,2bis(isocyanomethyl)propane (1) belongs to the reduced symmetry group $S_{4}$ and not as expected to $T_{\mathrm{h}}, T$, or $T_{\mathrm{d}}$. The NMR of 1 is accordingly simple showing only one signal in the ${ }^{1} \mathrm{H}$ NMR for the methylene group at $3.83 \mathrm{ppm}$ (ESI $\dagger$ ). The ${ }^{13} \mathrm{C}$ NMR is equally simple showing three signals corresponding to the central quaternary carbon at $39.1 \mathrm{ppm}$, the methylene carbons at $42.7 \mathrm{ppm}$, and the terminal isocyanide carbons at 160.9 ppm. Surprisingly, no signal in the carbon NMR spectrum shows a triplet as many other isocyanides do. The corresponding IR spectrum also reveals the for isocyanide groups typical strong absorption at $2148 \mathrm{~cm}^{-1} \cdot{ }^{17}$ The identity of compound 1 was also confirmed by X-ray single-crystal analysis (Fig. 2 \& ESI $\dagger$ ). The distance of the triple bond between $\mathrm{C}$ and $\mathrm{N}$ is comparable with many other isocyanides exhibiting a length of $1.16 \AA$. Interestingly, the negatively polarized isocyanide $\mathrm{C}$ is also forming a hydrogen bond to a hydrogen atom of a neighbouring tetraisocyanide molecule with $2.59 \AA$ A distance.

Having successfully synthesised the tetraisocyanide 1, we investigated its potential in multicomponent reactions (MCR). For this purpose, we decided to implement it in a fourfold Ugi four-component reaction. For the optimisation studies we chose acetic acid, phenylethylamine, and paraformaldehyde as substrates to not further introduce a symmetry break. The first attempt for the U4CR was performed under conventional conditions. Carrying out the reaction in $\mathrm{MeOH}(1 \mathrm{M})$ at room temperature led to the detection of traces of the desired product 12 after 3 days (Table 1, entry 1 ).
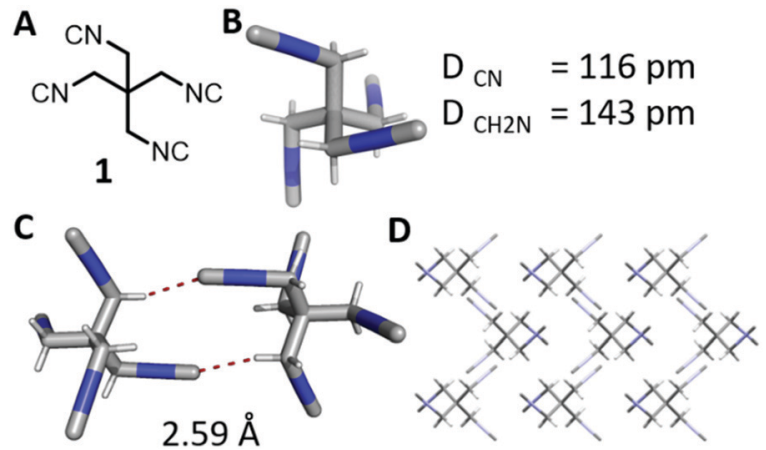

Fig. 2 (A) 2D-structure of 1; (B) crystal structure of 1 with corresponding bond lengths; (C) visualisation of intermolecular interactions of $2.59 \AA$ between isocyano group and methylene group; (D) visualisation of the crystal structure of 1 along the $X$-axis.

Increasing the reaction temperature to $60{ }^{\circ} \mathrm{C}$ (Table 1 , entry 2 ) or the reaction time to 21 days (Table 1 , entry 3 ) did not show any improvement. Therefore, we decided to apply microwave radiation for further optimisation reactions (Table 1, entries 4-13). The first attempts with microwave heating (Table 1, entries 4 and 5) demonstrated a diminished presence of unidentified side products compared to entries 1-3. The addition of catalytic amount of zinc chloride surprisingly eliminated any presence of the desired product 12 (Table 1, entry 6) and consequently, we continued optimisation without additional catalyst. The attempt to improve product formation by increasing equivalents

Table 1 Optimisation studies of fourfold U4CR-product $12^{a}$

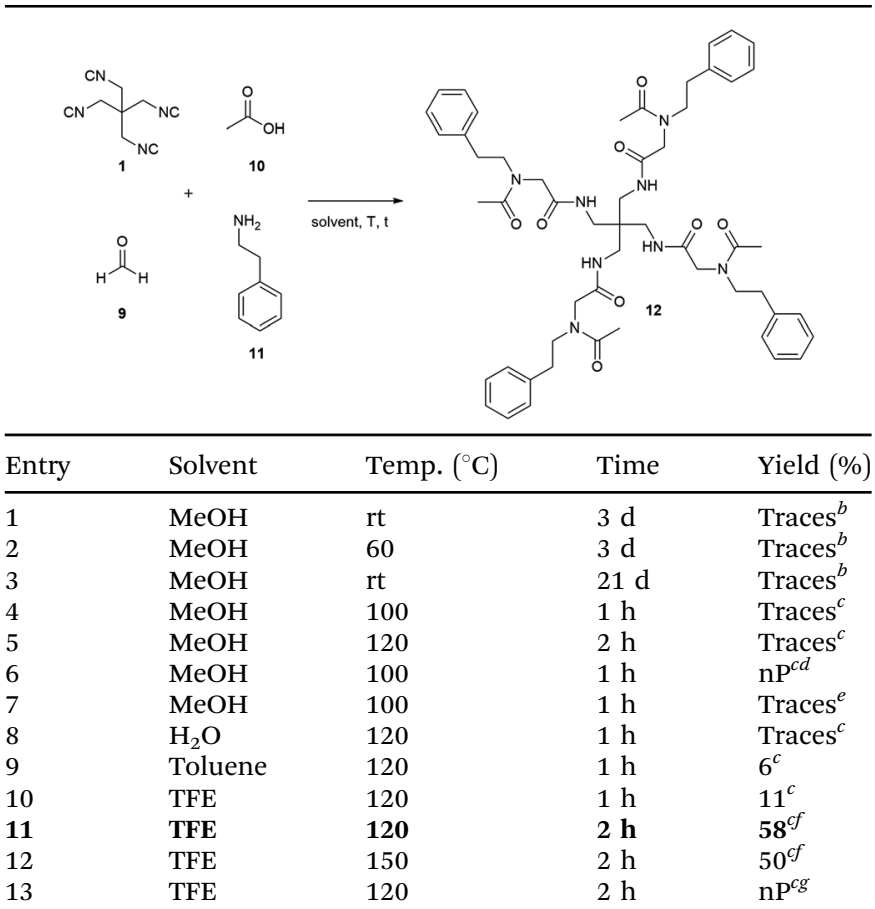

${ }^{a}$ All reactions were performed using $1(0.25 \mathrm{mmol}), \mathbf{9}(1 \mathrm{mmol}), 10(1 \mathrm{mmol})$, $11(1 \mathrm{mmol})$ and solvent $(1 \mathrm{~mL}) .{ }^{b} \mathrm{No} /$ conventional heat source. ${ }^{c}$ Microwaveassisted heating. ${ }^{d} 5 \mathrm{~mol} \% \mathrm{ZnCl}_{2} .{ }^{e} 8$ eq. of $\mathbf{9}, \mathbf{1 0}$, and $11 .{ }^{f}$ Beforehand stirring of $\mathbf{1 0}$ and $\mathbf{1 1}$ for $30 \mathrm{~min}$ at rt. ${ }^{g}$ Beforehand stirring of $\mathbf{1 0}$ and $\mathbf{1 1}$ for $30 \mathrm{~min}$ at $\mathrm{rt}$ and using 16 eq. of $\mathbf{9}$. nP: no product formed. 
of all substrates except the isocyanide resulted in no improvement compared to previous reactions. Based on the poor solubility of the isocyanide we decided to explore the effect of different solvents on the reaction employing water, toluene, and 2,2,2-trifluoroethanol (TFE) as solvents. Water could not achieve any improvement as opposed to toluene and TFE. Both, toluene and TFE demonstrated a significant improvement in product formation with yields for the isolated compound 12 of $6 \%$ and $11 \%$, respectively (Table 1, entries 9 and 10). Based on these findings we chose the sole use of TFE for further optimisation of the fourfold Ugi four-component reaction.

During the optimisation process, we formulated the hypothesis that the isocyanide is not stable in the presence of free acid and therefore degrades in the reaction mixture. ${ }^{18,19}$ Consequently, we changed the addition order to confirm indirectly this hypothesis. We mixed the amine substrate 11, the acid substrate 10 , and TFE $(0.5 \mathrm{~mL})$ in advance and stir the reaction mixture at room temperature for $30 \mathrm{~min}$ expecting an acid-base reaction and hence reducing the amount of free acid. Adding paraformaldehyde (9) and the tetraisocyanide $\mathbf{1}$ afterwards and carrying out the reaction with microwave-assisted heating yielded the desired product 12 in 58\% (Table 1, entry 11). Further attempts of improvement by increasing the reaction temperature to $150{ }^{\circ} \mathrm{C}$ (Table 1 , entry 12) or by increasing the equivalents of paraformaldehyde (9) (Table 1, entry 13) led to reduced yields or even no product formation at all.

Having accomplished and optimised this fourfold multicomponent reaction with satisfactory yields, we explored the scope and limitations of the U4CR using the tetraisocyanide $\mathbf{1}$, paraformaldehyde (9), and diverse acid (A) and amine (B) components, as shown in Table 2.

Remarkably, many different amine and acid sources were compatible in the fourfold U4CR with yields of 35-83\% showing a great functional group tolerance and generally disregarding steric or electronic factors. Various aliphatic amines, including propargylamine, 3-picolylamine, tert-butylamine, and 2,2-diphenyl ethylamine, as well as aliphatic acids, including 3-(2-furyl)acrylic acid, 2-cyclohexylacetic acid, and 5-hexynoic acid, yielded the corresponding fourfold U4CR product. Moreover, aromatic acids, for example, picolinic acid, 3,4,5-trimethoxybenzoic acid, and 2-methyl-3-nitrobenzoic acid, were able to react in the fourfold U4CR reaction. Despite the high functional group tolerance, certain substrates did not result in product formation. Utilising any sort of anilines and substrates including an indole or pyrrole function did not generate any traces of product. Noteworthy, the reaction with $\mathrm{N}$-(tert-butoxycarbonyl) glycine (Table 2, entry 13h) as acid source showed the lowest yield overall. The combination of fluorinated solvents and microwave radiation, as demonstrated by Choy et al., is capable of Boc-deprotection which explains the atypical low yield. ${ }^{20}$ Overall, 11 fourfold Ugi 4CR compounds were successfully synthesised. Besides, we were able to produce two single-crystals from the products of entry $\mathbf{1 3 b}$ and $\mathbf{1 3 e}$ confirming by X-ray singlecrystal analyses the fourfold U4CR products (Fig. 3).

Both crystal structures (Fig. 3) show intramolecular hydrogen bonds depicted in a ring motif around the central carbon; these interactions consist of hydrogen bonds between the core
Table 2 Synthesis of U4CR-products ${ }^{a}$

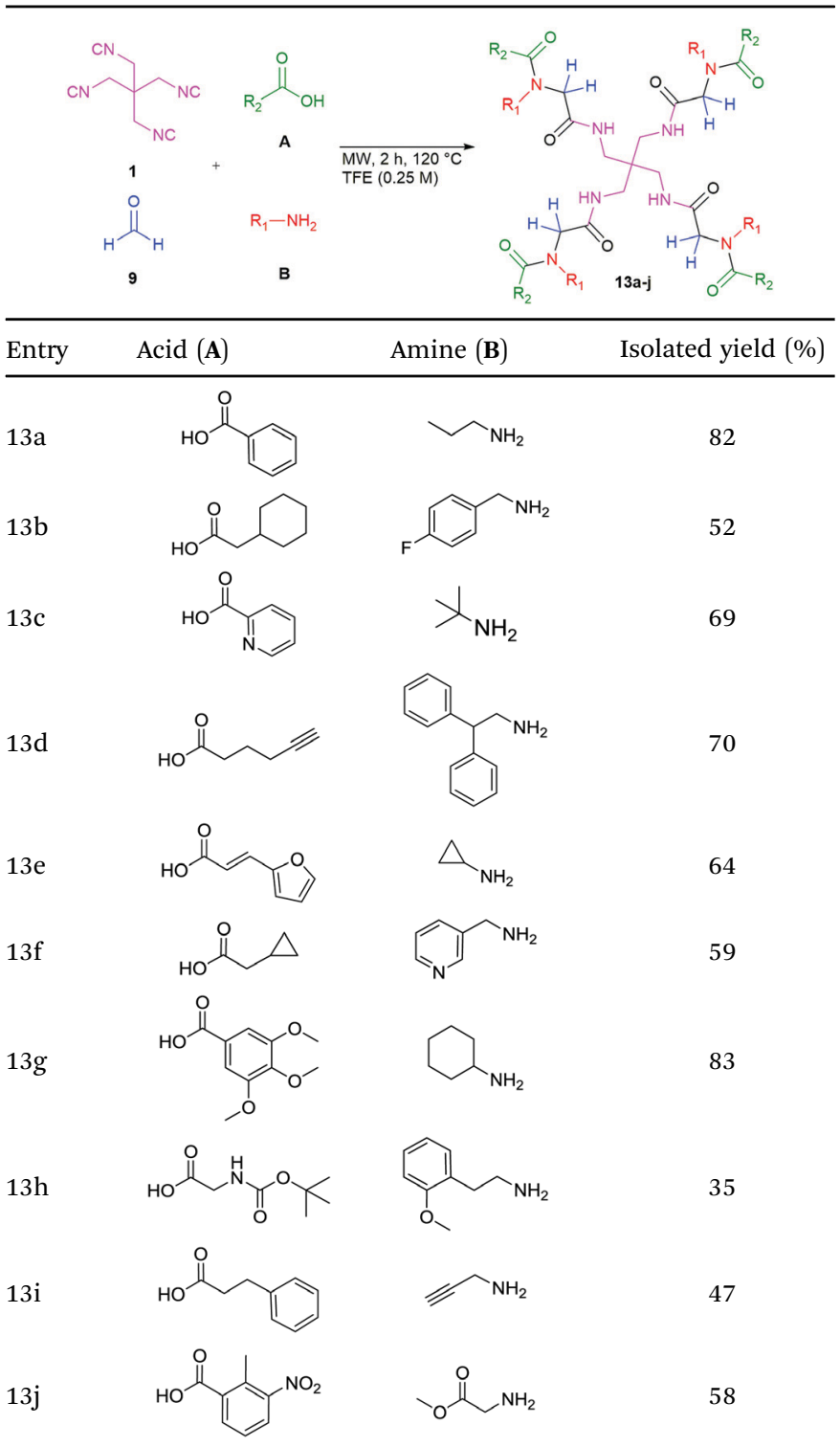

${ }^{a}$ All reactions were performed using $1(0.25 \mathrm{mmol}), 9(1 \mathrm{mmol})$, acid A $(1 \mathrm{mmol})$, amine $\mathbf{B}(1 \mathrm{mmol})$, and TFE $(1 \mathrm{~mL})$ using the optimised reaction conditions (Table 1 , entry 11$)$.

amides. Additionally, 13e shows intermolecular hydrogen bonds with a residual methanol molecule breaking the $S_{4}$ symmetry exhibited by 1 \& $\mathbf{1 3 b}$ and reducing it to $C_{1}$ symmetry. Following the U4CR, we implemented the tetraisocyanide 1 also in a fourfold Passerini three-component reaction. The optimised reaction conditions of the U4CR were adjusted for the P3CR by switching the solvent from TFE to 1,2-dichloroethane. The absence of an amine component was compensated by the addition of four equivalents of triethylamine to account for the acid lability of $\mathbf{1}$.

To evaluate the scope and limitations of the P3CR with the tetraisocyanide 1, phenylacetic acid, 3,4,5-trimethoxybenzoic acid, 2-methyl-3-nitrobenzoic acid, picolinic acid, and 5-hexynoic acid were chosen as representative acids. All the engaged acids yielded 

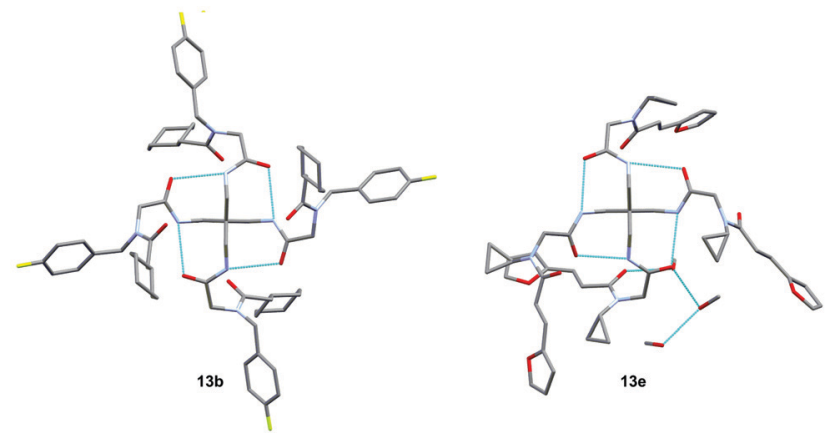

Fig. 3 Crystal structures of $\mathbf{1 3 b}$ and $\mathbf{1 3 e}$; shown in blue are the existing hydrogen bonds with lengths of $2.86 \AA$ (13b) and $2.87 \AA$ (13e) between the core amide bonds, and a length of $2.68 \AA$ between one amide bond of $13 \mathrm{e}$ and a residual methanol molecule.

Table 3 Synthesis of P3CR-products ${ }^{a}$

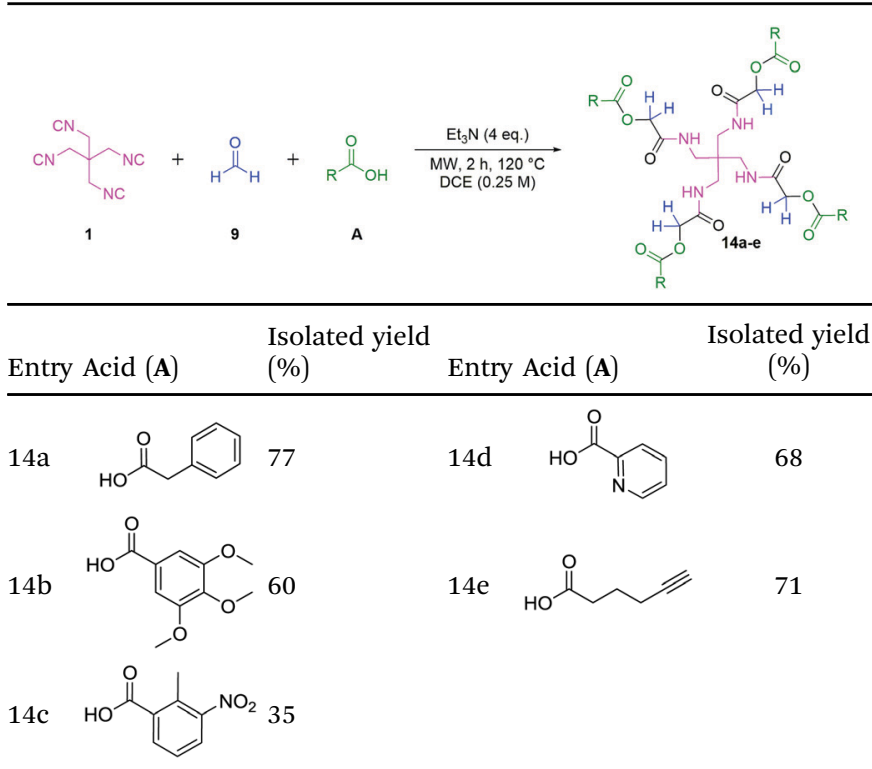

${ }^{a}$ The Passerini reactions were performed with adapted optimised reaction conditions of entry 11 of Table 1 using $1(0.25 \mathrm{mmol}), 9(1 \mathrm{mmol})$, acid A $(1 \mathrm{mmol})$, triethylamine $(1 \mathrm{mmol})$ and DCE as solvent $(1 \mathrm{~mL})$.

in the corresponding fourfold Passerini product with $35-77 \%$ representing a high functional group tolerance. Only electronpoor aromatic acids, i.e. 2-methyl-3-nitrobenzoic acid, generated low yields in the P3CR reaction for product 14c (Table 3).

In essence, we were able to introduce 1,3-diisocyano-2,2bis(isocyano-methyl)propane (1) of $S_{4}$ symmetry by a short four - step synthesis route showing great scalability with an overall yield of $44 \%$. Furthermore, the synthesis of 16 fourfold IMCR compounds employing the tetraisocyanide 1 were accomplished and confirmed by X-ray single-crystal analyses. Showing great compatibility with the U4CR and the P3CR, we were able to generate unique novel four-legged scaffolds proving the great potential of the tetraisocyanide 1. By demonstrating high functional group tolerance and moderate to high yields, the tetraisocyanide 1 can be envisioned for numerous exciting novel applications such as MOFs, COFs, IMCR-based dendrimers, and other materials. Corresponding investigations are ongoing in our lab and will be reported in due course.

This research has been supported by the National Institute of Health (NIH) (2R01GM097082-05), the European Lead Factory (IMI) (grant agreement number 115489), the Qatar National Research Foundation (NPRP6-065-3-012), COFUNDs ALERT (grant agreement no. 665250), Prominent (grant agreement no. 754425) and KWF Kankerbestrijding grant (grant agreement no. 10504). K. K. and J. K.-T. acknowledge the financial support of the European Regional Development Fund in the framework of the Polish Innovation Economy Operational Program (contract no. POIG.02.01.00-12-023/08) for equipment purchase.

\section{Conflicts of interest}

There are no conflicts to declare.

\section{Notes and references}

1 A. Dömling, Chem. Rev., 2006, 106, 17-89.

2 J. W. Collet, T. R. Roose, E. Ruijter, B. U. W. Maes and R. V. A. Orru, Angew. Chem., Int. Ed., 2020, 59, 540-558.

3 M. Ayaz, F. De Moliner, J. Dietrich and C. Hulme, Isocyanide Chem., 2012, 335-384.

4 I. Ugi, et al., Organic Chemistry, Volume 20: Isonitrile Chemistry, Academic Press, Inc., London, New York, 1971.

5 C. Cordovilla, S. Coco, P. Espinet and B. Donnio, J. Am. Chem. Soc., 2010, 132, 1424-1431.

6 S. Krawielitzki and W. Beck, Chem. Ber., 1997, 130, 1659-1662.

7 D. G. Rivera, F. León, O. Concepción, F. E. Morales and L. A. Wessjohann, Chem. - Eur. J., 2013, 19, 6417-6428.

8 D. G. Rivera and L. A. Wessjohann, J. Am. Chem. Soc., 2009, 131, 3721-3732.

9 D. G. Rivera and L. A. Wessjohann, J. Am. Chem. Soc., 2006, 128, 7122-7123.

10 M. G. Hill, M. C. Comstock and K. R. Mann, J. Org. Chem., 1990, 55, 4950-4951.

11 J. Gagnon, M. Drouin and P. D. Harvey, Inorg. Chem., 2001, 40, 6052-6056.

12 N. Elders, D. van der Born, L. J. D. Hendrickx, B. J. J. Timmer, A. Krause, E. Janssen, F. J. J. de Kanter, E. Ruijter and R. V. A. Orru, Angew. Chem., Int. Ed., 2009, 48, 5856-5859.

13 Y. Ito, K. Kobayashi and T. Saegusa, J. Organomet. Chem., 1986, 303, 301-308.

14 M. Toriyama, T. R. Maher, T. C. Holovics, K. Vanka, V. W. Day, C. L. Berrie, W. H. Thompson and M. V. Barybin, Inorg. Chem., 2008, 47, 3284-3291.

15 A. Dömling and I. Ugi, Angew. Chem., Int. Ed., 2000, 39, 3168-3210.

16 T. Zarganes-Tzitzikas, A. L. Chandgude and A. Dömling, Chem. Rec., 2015, 15, 981-996.

17 R. W. Stephany, M. J. A. de Bie and W. Drenth, Org. Magn. Reson., 1974, 6, 45-47.

18 A. M. van Leusen, B. E. Hoogenboom and H. Siderius, Tetrahedron Lett., 1972, 13, 2369-2372.

19 F. Millich, Chem. Rev., 1972, 72, 101-113.

20 J. Choy, S. Jaime-Figueroa, L. Jiang and P. Wagner, Synth. Commun., 2008, 38, 3840-3853. 